Cevher-Keskin, B., Quantitative mRNA Expression Profiles of Germin-Like and Extensin-Like Proteins under Drought Stress in Triticum aestivum. International Journal of Life Sciences and Biotechnology, 2019. 2(2): p. 95-107.

\title{
Quantitative mRNA Expression Profiles of Germin-Like and Extensin-Like Proteins under Drought Stress in Triticum aestivum
}

\author{
Birsen Cevher-Keskin ${ }^{1}$
}

\begin{abstract}
Drought stress can severaly damage plant growth and the most important factor in the reduction of wheat yield in cultivated areas. Development of new methodologies to improve wheat productivity and quality under drought conditions have a primary importance. Extensin-like (TaExtLP) and Germin-like Protein $(T a G L P)$ transcripts were selected from our RNAseq data for their relation with defense mechanism. We aim to show the expression patterns of these genes in drought tolerant (Gerek 79 and Müfitbey) and non-tolerant T. aestivum (Atay) cultivars under drought stress conditions using qRTPCR technique. Extensin is the most abundant proteins present in the cell wall of higher plants and has an important role in plant defense through strengthening the cell wall and preventing tissue damage. GLPs are involve in different biological processes; e.g., disease resistance and superoxide scavenging metabolism. We established different mRNA expression regulation of Extensin like and Germin-like mRNAs in root and leaf tissues of tolerant and non-tolerant T. aestivum cultivars under drought stress. We observed GLP transcript was significantly up-regulated ( 5 fold) in $4 \mathrm{~h}$ drought- stressed root tissues of tolerant cultivar Gerek and then decreased in $8 \mathrm{~h}$. On the other hand, there was no dramatic difference in leaf tissue of each cultivar. Extensin-like gene up-regulation was approximately 6 and 3.5 fold in $4 \mathrm{~h}$ stressed root tissues of tolerant cultivars. In leaf tissues, different expression pattern was observed in tolerant and non-tolerant cultivars. Drought stress caused to up-regulation (4 fold) in $4 \mathrm{~h}$ stressed leaf tissues of tolerant cultivar. On the contrary, down-regulation (4 fold) was identified in non-tolerant stressed leaf tissues. These results suggest that overexpression of Extensin-like gene under drought stress conditions may enhance drought tolerance. The qRT-PCR results from root and leaf tissues from 3 different cultivars were in agreement with our previous RNAseq data. This is the first report shows the expression profiles of these defense proteins under drought stress conditions in T. aestivum.
\end{abstract}

\author{
ARTICLE HISTORY \\ Received \\ 17 May 2019 \\ Accepted \\ 25 June 2019
}

\section{Introduction}

Bread wheat, Triticum aestivum L. is one of the main fundamental crops for many countries including Turkey. Drought is the major factor affecting wheat yields throughout the world however; it is more problematic factor for wheat agriculture in arid regions

\footnotetext{
${ }^{1}$ The Scientific and Technological Research Council of Turkey (TUBITAK); Marmara Research Center; Genetic Engineering and Biotechnology Institute; Plant Molecular Biology and Genetics Laboratory, P.O Box: 21, 41470 Gebze, Kocaeli /Turkey.

*Corresponding author e-mail: bcevherkeskin@gmail.com; birsen.keskin@ tubitak.gov.tr
} 
including central and eastern Anatolian regions of Turkey. Especially in central Turkey, yield losses could reach up to $80 \%$ in some years (http://www.turkstat.gov.tr). Therefore, development of new methodologies to improve wheat productivity and quality under drought conditions has a primary importance. Improvement in wheat breeding for drought tolerance is difficult because of the complexity of quantifying and measuring drought traits.

In higher plants, drought stress causes physiological changes, including loss of turgor, reduced leaf water potential and osmotic adjustment $[1,2]$. Turgor pressure is a crucial factor for cell growth regulation. The management of cell enlargement depends on the cell wall extensibility [3, 4]. Water stress causes a low turgor pressure and then leads regression of growth by reducing cell extensibility and cell expansion [5]. From our previous studies, drought-stress related genes were identified in Triticum aestivum (bread wheat) cultivars under drought conditions by RNASeq technology (Illumina HiSeq2000) [6]. The selection of most promising drought stress tolerant and sensitive genotypes was performed by slow drought treatment experiments with three biological replications for 12 bread wheat cultivars. Three of them were selected as drought tolerant (Gerek 79 and Müfitbey) and non-tolerant (Atay-85) bread wheat cultivars based on the results of the physiological and biochemical analyses [6]. From RNAseq data, we selected differently expressed Extensin-like protein (TaExtLP) and Germin-like (TaGLP) proteins important for the defense mechanism in biotic stress $[7,8,9]$. In this report, we aimed to investigate mRNA expression profiles of these genes in the root and leaf tissues of different $T$. aestivum cultivars under drought stress conditions. As a member of the family of Hyprich glycoproteins (HRGPs), extensin is the most abundant protein group present in the cell wall of higher plants and regulated developmentally in a tissue-specific [7, 8]. They play an important role in plant defense through strengthening the cell wall, preventing tissue damage, enabling attachment of symbiotic organisms or limiting the pathogen invasion and propagation. Germins and GLPs were firstly reported in wheat as a specific marker for the start of germination [9]. Dwarfism induction, cell morphology changes and disease increase (sheath blight and blast fungal) were observed in GLP1 downregulated in transgenic O. sativa [10]. 
We aim to illuminate the mRNA expression profiles of Extensin-like and Germin-like proteins under shock dehydration stress conditions in showing different drought tolerance T. aestivum cultivars. QRT-PCR analyses were performed for these defense proteins in the root and leaf tissues under normal and two different dehydration stress conditions.

\section{Materials and Methods}

\section{Growth conditions}

Three T. aestivum cultivars Gerek 79 and Müfitbey (drought-tolerant) and Atay 85 (nontolerant) were used in this study. Seeds were surface sterilized with $70 \%$ alcohol and $30 \%$ sodium hypochlorite and pre-germinated in Petri dishes for 10 days at $4{ }^{\circ} \mathrm{C}$ in the dark. Seedlings were transferred to $10 \mathrm{~L}$ plastic pots containing moistened perlite after the germination and grown in a plant growth room under $16 / 8 \mathrm{~h}$; temperature $22-18^{\circ} \mathrm{C}$; relative humidity $60 \%$. Seedlings that at the same developmental stage were moved to hydroponic (continuously aerated $1 / 2$ Hoagland's solution) culture, renewed every 3 days, and grown under controlled conditions in the plant growth room. Plants were removed from the hydroponic culture at the age of four leaf stage and treated dehydration shock stress for $4 \mathrm{~h}$ and $8 \mathrm{~h}$ under the same temperature and light conditions. From 3 wheat varieties ( 2 drought tolerant and 1 non-tolerant) root and leaf tissues were harvested and frozen with corresponding controls and stored $-80^{\circ} \mathrm{C}$ until RNA isolation [11].

\section{RNA extraction and cDNA synthesis}

Total RNA extraction was performed by using the RNeasy Plant Mini Kit (Qiagen, Valencia, CA) from 3 different $T$. aestivum cultivars according to the manufacturer's instructions. Extracted high-purity total RNAs from $4 \mathrm{~h}$ and $8 \mathrm{~h}$ drought stressed and corresponding control root and leaf tissues were measured by nanodrop (Thermo). RNA samples were treated with DNase I (10 U) (Roche, GmbH, Germany) for removing residual genomic DNA and purified following to the method described previously [12]. The integrity of RNA samples was controlled by running on $1 \%$ formaldehyde agarose gel and first-strand cDNA synthesis was performed to the manufacturer's (Roche High Fidelity cDNA synthesis kit) instructions in a $20 \mu$ final volume containing $5 \mu \mathrm{g}$ total RNA, 200 U MMLV RTase, 100 pmol oligo-dT (18 mer), 15 pmol dNTPs, and $20 \mathrm{U}$ RNase inhibitor [12]. 


\section{Quantitative real-time PCR}

qRT-PCR reactions contained 75-200 ng of the cDNA as a template, 10 pmole of each primer, $12.5 \mu$ S SYBR Green (Roche FastStart Universal SYBR Green Master, Rox) in a total volume of $25 \mu \mathrm{l}$. QRT-PCR experiments were carried out in 96 well polypropylene plates and performed in triplicate for each sample with IQ5 System (BioRad, Hercules, USA). The following standard thermal profile was employed: After $95^{\circ} \mathrm{C}$ for 5 min for polymerase activation, amplification and quantification cycles (45 times) $95^{\circ} \mathrm{C}$ for $30 \mathrm{~s}$, $55^{\circ} \mathrm{C}$ for $1 \mathrm{~min}$. Melting-curve analysis was carried out for the specificity of the primer pairs after 45 amplification cycles $\left(55-95^{\circ} \mathrm{C}\right)$. Housekeeping gene $\beta$-actin was used (AY663392) as an internal control. The following primer pairs (Table 1) were designed to amplify a 115-bp TaExtLP fragment and a 102 bp TaGLP 9.1 fragment. All the primers used in qRT-PCR experiments were designed by Primer 3 program. Three technical replicates were carried out in order to quantify transcript level accurately. The $\Delta \Delta \mathrm{Cq}$ values for all the transcripts were averaged across all the treatments and experimental replicates. Student's t-test (GraphPad Prism 6) was applied to check for the statistical significance between drought-treated and -untreated control groups.

Table 1 QRT-PCR Primer list

\begin{tabular}{|c|c|c|}
\hline Primer Name & Sequence 5 '-3' & $\begin{array}{l}\text { Product } \\
\text { Size }\end{array}$ \\
\hline$\beta$-Actin F & GACAA TGGAACCGGAATGGTC & $110 \mathrm{bp}$ \\
\hline$\beta$-Actin R & GTGTGATGCCAGATTTTCTCCATg & \\
\hline TaExtLP F & AACCAGGGAAAACACAT CTT & $115 \mathrm{bp}$ \\
\hline TaExtLP R & GGCAACAACAACAACAACTA & \\
\hline TaGLP 9.1 F & CACCAG GGATCACTAGACTA & $102 \mathrm{bp}$ \\
\hline TaGLP 9.1 R & TGTCCGGAA ATCATGAAACT & \\
\hline
\end{tabular}




\section{Results}

From our RNAseq data, we found Germin-like protein 9-1 and Extensin-like protein gene expressions were differentially expressed in root and shoot tissues [6]. The abundance of TaExtLP and TaGLP 9-1 mRNA under $4 \mathrm{~h}$ and $8 \mathrm{~h}$ shock drought stress treatment was examined in root and leave tissues of drought tolerant and non-tolerant T. aestivum genotypes (Fig. 1).

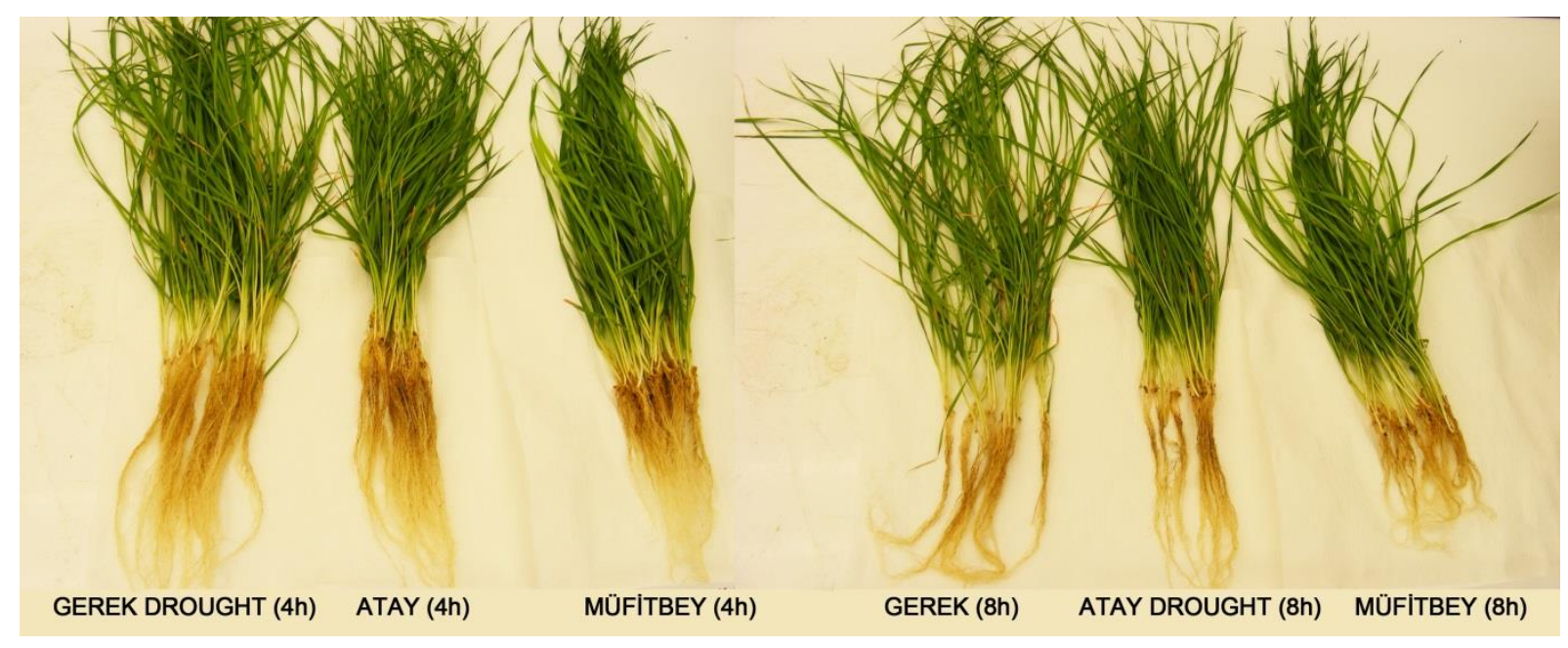

Fig 1 Drought non-tolerant Atay85, Drought tolerant Müfitbey, and Gerek 79 T. aestivum cultivars

After total RNA extraction from root and leaf tissues, removal of genomic DNA was carried out. Semi-quantitative RT-PCR method was used to control the synthesized cDNAs (Fig 2).

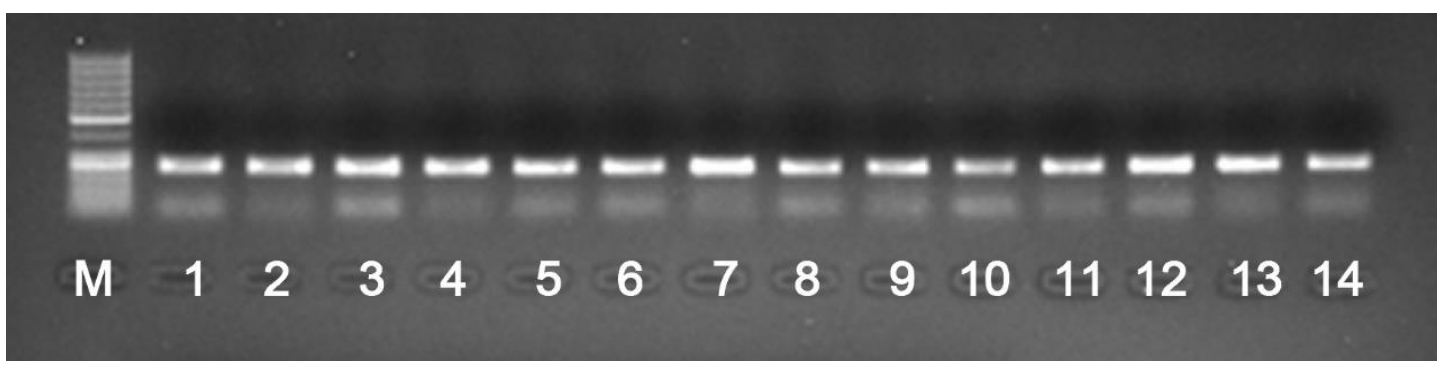

Fig 2 Agarose gel electrophoresis of amplified first-strand cDNAs by semi-qRT-PCR with housekeeping $\beta$-actin gene primers (M: GeneRuler 100bp DNA Ladder, MBI Fermentas)

Extensin-like protein (Arabidopsis, cell wall extensin) mRNA Expression: Extensinlike protein is the most abundant protein group present in the cell wall of higher plants 
$[7,13]$. Extensin expression in response to wounding, pathogen infection and ethylene treatment supports for the role of extensins in plant defense $[14,15,16,17,8]$. In our qRT-PCR experiments, it was observed that drought stress caused the up-regulation of this gene in root tissues. Maximum mRNA expression was observed in $4 \mathrm{~h}$ droughtstressed root tissues of tolerant and non-tolerant genotypes (Fig 3A, B, and C) .

In leaf tissues, TaExtLP mRNA was dramatically increased under $4 \mathrm{~h}$ drought-stressed Müfitbey.
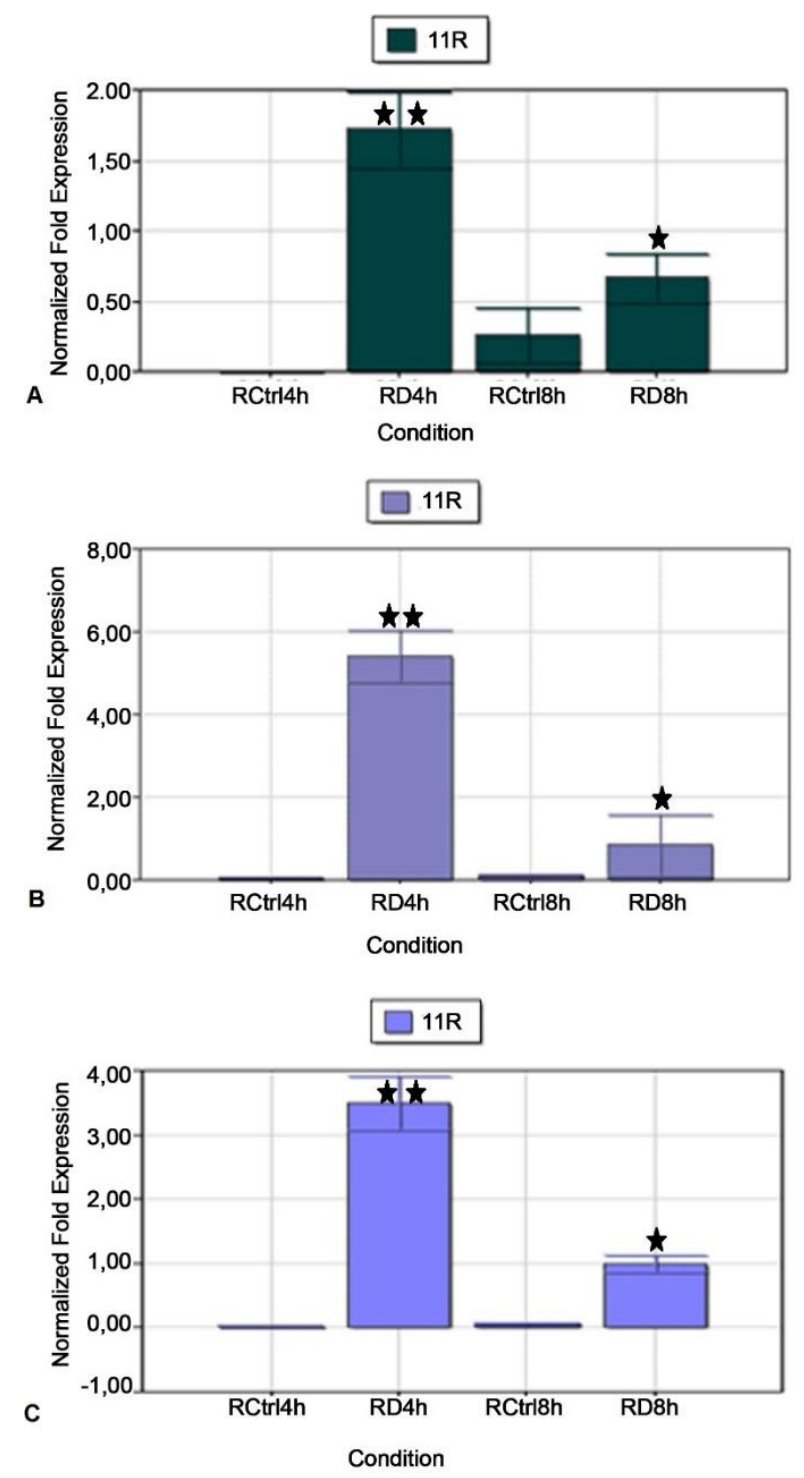

Fig 3 mRNA expression pattern of TaExtLP (cell wall) in $4 \mathrm{~h}$ and $8 \mathrm{~h}$ drought stressed root tissue of drought non-tolerant genotype Atay 85 (A), and Gerek (B), Müfitbey (C) cultivars. RCtrl: Root Control 4 h, RD4h: Root Drought 4 h. RCtrl8h: Root Control 8 h, RD8h: Root Drought 8 h. Error bars indicate the standard deviation of qRT-PCR each performed in triplicate. $\left(^{*}\right)$ : $p$ $\leq 0.05,(* *): p \leq 0.01$. 
On the other hand, Ext-like protein mRNA transcript was not much changed compared to the control tissue in $4 \mathrm{~h}$ drought stressed leaf tissues in non-tolerant genotype Atay. After $8 \mathrm{~h}$ of drought, mRNA expression level was not changed in leaf tissues (Fig 3).

Conversely, the different expression pattern was observed in leaf tissue of tolerant and non-tolerant genotypes. In non-tolerant genotype Atay 85, maximum mRNA was observed in $4 \mathrm{~h}$ drought stress treated leaf tissue and there was no significant difference in $8 \mathrm{~h}$ drought stress (Fig 4A). Whereas in the same tissue, down-regulation of this gene was shown in tolerant genotype Müfitbey (Fig 4B) and Gerek (data not shown).
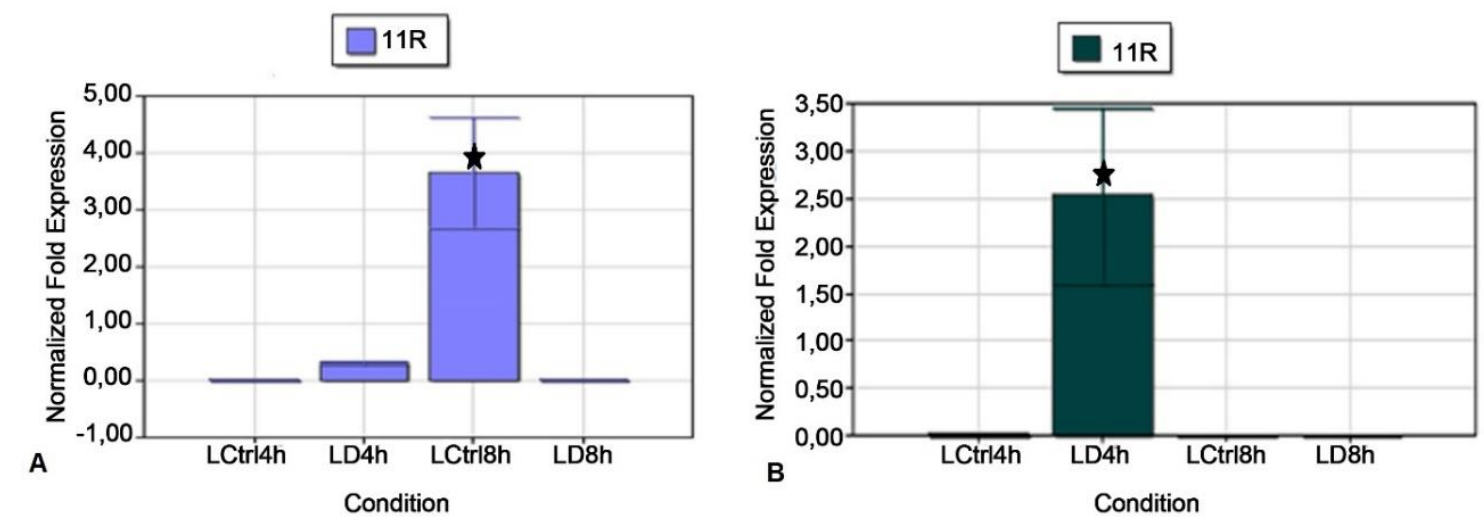

Fig 4 mRNA expression pattern of TaExtLP (cell wall) in $4 \mathrm{~h}$ and $8 \mathrm{~h}$ drought stressed leaf tissue of drought non-tolerant genotype Atay 85 (A), and non-tolerant Müfitbey (B) cultivars. LCtrl4h: Leaf Control 4 h, LD4h: Leaf Drought 4h, LC8h: Leaf Control 8h, LD8h: Leaf Drought 8h. Error bars indicate the standard deviation of qRT-PCR each performed in triplicate. $\left(^{*}\right): p \leq 0.05$.

Germin-like proteins (GLPs) have been shown to implicate as plant cell defenders in many species to different conditions and diseases [19]. In root tissue, GLP9-1 mRNA expression was induced by $4 \mathrm{~h}$ and $8 \mathrm{~h}$ drought stress (Fig 5A, B, and C). In the leaf tissue of non-tolerant genotype, there was no dramatic difference between control and drought stress. On the contrary, up-regulation was obtained in $4 \mathrm{~h}$ and $8 \mathrm{~h}$ drought stressed leaf tissues of tolerant genotype Müfitbey (Fig 6 B). 

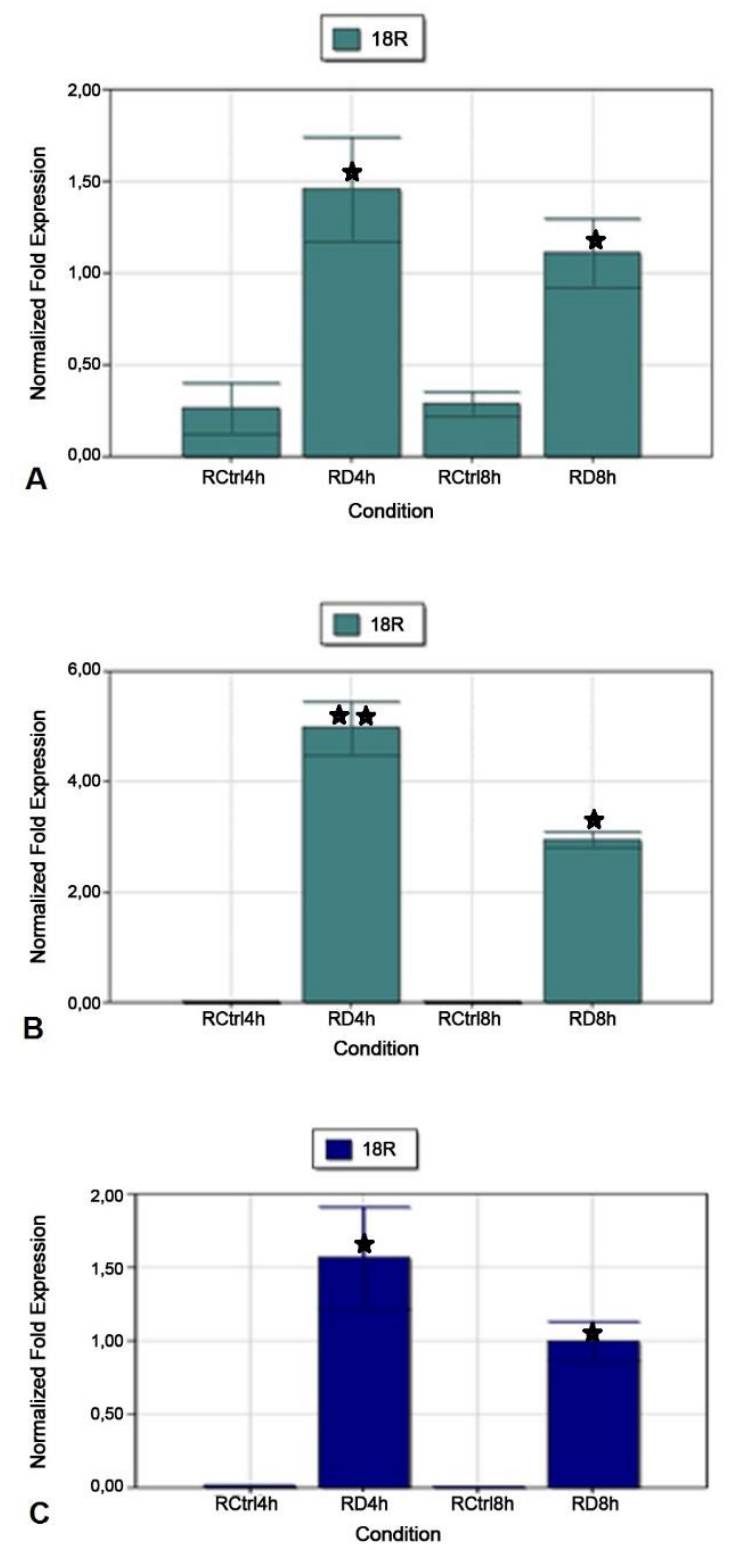

Fig 5 mRNA expression profile of GLP9- 1 in $4 \mathrm{~h}$ and $8 \mathrm{~h}$ drought stressed root tissue of drought non-tolerant genotype Atay 85 (A), and Gerek (B), Müfitbey (C) cultivars. RCtrl: Root Control 4h, RD4h: Root Drought 4h. RCtrl8h: Root Control 8h, RD8h: Root Drought 8h. Error bars indicate the standard deviation of qRT-PCR each performed in triplicate. $(*): p \leq 0.05,(* *): p$ $\leq 0.01$.

In root tissue, GLP9-1 mRNA expression was induced by $4 \mathrm{~h}$ and $8 \mathrm{~h}$ drought stress (Fig $5 \mathrm{~A}, \mathrm{~B}$, and $\mathrm{C}$ ). In the leaf tissue of non-tolerant genotype, there was no significant difference between control and drought stress. On the contrary, up-regulation was observed in $4 \mathrm{~h}$ and $8 \mathrm{~h}$ drought stressed leaf tissues of tolerant genotypes Müfitbey (Fig 6 B) and Gerek (data not shown). 

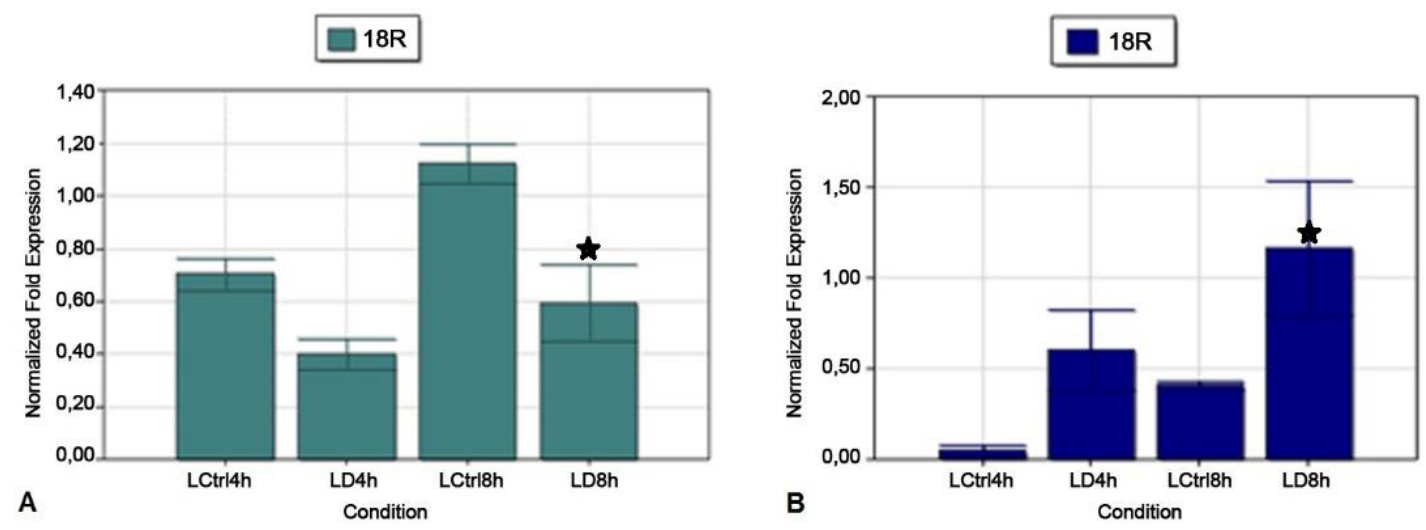

Fig 6 mRNA expression profile of GLP9-1 in $4 \mathrm{~h}$ and $8 \mathrm{~h}$ drought stressed leaf tissue of drought non-tolerant genotype Atay 85 (A), and non-tolerant Müfitbey (B) cultivars. LCtrl4h: Leaf Control 4 h, LD4h: Leaf Drought 4 h, LC8h: Leaf Control 8h, LD8h: Leaf Drought 8h. Error bars indicate the standard deviation of qRT-PCR each performed in triplicate. $\left(^{*}\right): \mathrm{p}$ $\leq 0.05$.

\section{Discussion}

Extensin-like and Germin-like-genes are expressed in an organ-specific fashion and stress-related proteins in plants. Extensins are implicated in different biological processes such as embryonic development [20], root hair growth [21, 22], cell wall assembly and structure [23, 24], and biotic and abiotic stress responses [18, 25, 26]. Increased extensin accumulation and extensin cross-linking has been suggested to help in wound recovery and in the formation of a physical barrier against pathogens, thus avoiding the entry of pathogens into the vascular system [27]. In higher plants, the immune response can differ between leaf and root tissues [28, 29]. RNAseq data from A. thaliana showed that a significant number of genes ( 2424 genes) were differentially expressed between shoots and roots under normal conditions. Root-overexpression of at least nine encoded extensin proteins suggested specific roles of these glycoproteins in root tissues [30]. Glycine max extensin gene, $S b H R G P 3$, expression has been shown in hypocotyl and the roots of seedlings [13]. In tomato, LeExt1, an Extensin-like protein expression was observed with tip growth, which proposes a role of the LeExt1 protein in root hair expansion. Comparative transcript analysis of LeExt1/GUS chimeric gene in four different transgenic plant species has proven its role in the regulation of apical/basal polarity in root tissues of transgenic tomato [31]. As a cell wall protein, extensins are also released into the root mucilage. Recently, Castilleux et al [32] reported a model about the influence of cell wall extensin on root secretions. 
Up-regulation of cell wall modification related proteins lead to changes in the cell wall composition [33]. Different Expansin (Exp) and Extensin (Xth) mRNA gene expression profiles were reported at low temperatures in Arabidopsis and rice [34]. Extensin (Xth) down-regulation was observed to cold stress in Arabidopsis [35]. Freezing tolerance was improved by the overexpression of AtXTH21in transgenic Arabidopsis plants [35].

The Extensin-like gene identified from our RNAseq data was significantly up-regulated (about 4 fold) in response to $4 \mathrm{~h}$ and $8 \mathrm{~h}$ dehydration stress [6]. In this study, Extensinlike gene up-regulation was approximately 6 and 3.5 fold in $4 \mathrm{~h}$ stressed root tissues Gerek and Müfitbey cultivars. In leaf tissues in tolerant and non-tolerant cultivars, the different expression pattern was observed. Drought stress caused to up-regulation (4 fold) in $4 \mathrm{~h}$ stressed leaf tissues of Müfitbey. On the contrary, down-regulation (4 fold) was identified in Atay $4 \mathrm{~h}$ stressed leaf tissues. These results suggest that Extensin-like gene may have a role in drought tolerance.

Germin-like protein 9-1 (Oryza sativa subsp. japonica - apoplast, manganese ion binding, nutrient reservoir activity): Germins and GLPs were firstly reported in wheat as a specific marker for the start of germination [36]. Different enzymatic activities of six germin subfamilies (GER1-6) were identified with e.g. OXO activity in GER1 and SOD activity in GER2 [10]. The GER1 subfamily has also been reported to be involved in early plant development and germination [37, 38]. Dwarfism induction, cell morphology changes and disease increase (sheath blight and blast fungal) were observed in GLP1 down-regulated in transgenic rice plants [19]. GLPs have been studied in different plant species and implicated as plant cell defenders to biotic and abiotic stress conditions. GLPs have been reported to be resistant to proteases, extreme $\mathrm{pH}$, heat, and sodium dodecyl sulphate [39].

GLP expression in H. vulgarae and a QTL on chromosome 8 of $O$. sativa have shown their involvement in disease resistance and complex trait of GLPs in cereal genomes [40, 41]. In our previous studies, we reported differential expression of GLP-like mRNA in ABA- treated wheat by DD mRNA experiments. In ABA-dependent pathway, GLP1 mRNA expression in ABA-treated plants rapidly increased in $1 \mathrm{~h}$ and maximal expression level was obtained in $8 \mathrm{~h}$ [40]. In the present study, we observed GLP transcript was significantly up-regulated ( 5 fold) in 4 h drought- stressed root tissues of tolerant cultivar 
Gerek and then decreased in $8 \mathrm{~h}$. On the other hand, there was no dramatic difference in leaf tissue of tolerant and non-tolerant cultivars. The qRTPCR results from root and leaf tissues from 3 different cultivars were in agreement with our RNAseq data.

\section{Conclusion}

The identification and elucidation of functional characteristics of the genes that play a role in the complex drought-response in wheat will be helpful for making the popular wheat varieties more productive with less amount of water. It is very significant to learn more about stress related genes for the elucidation of stress mechanism by transgenic plants. Although there are many studies about the Ext and GLP genes, the functions of these genes are still elusive. Downregulation or overexpression of Ext and GLP through gene editing methodology may shed more light on the functions of these genes in the future.

\section{Acknowledgement}

This work has been supported by the International Center for Genetic Engineering and Biotechnology (ICGEB) grand (\#CRP/TUR09-03) to B. Cevher-Keskin. Bread wheat cultivars were provided from Agriculture and Forestry Translational Zone Agricultural Research Institute (Turkey) and the Ankara Agricultural Research Institute (Turkey).

\section{Conflicts of Interest:}

The author declare no conflict of interest.

\section{Abbreviations}

qRT-PCR: quantitative real time PCR, TaGLP: Germin-Like Protein of T. aestivum, TaExtLP: Extensinlike Protein of T. aestivum, RNAseq: RNA sequencing

\section{References}

1. Shao, H.B., et al., Water-deficit stress-induced anatomical changes in higher plants. C. R. Biology, 2008. 331: p. 215-225.

2. Lisar, S.Y.S., et al., Water stress in plants: Causes, effects and responses. In Water Stress; Rahman, M., Hasegawa, H., Eds.; InTech: Rijeka, Croatia, 2012. p. 1-14.

3. Tardieu, F. Any trait or trait-related allele can confer drought tolerance: Just design the right

4. drought scenario. Journal Experimental Botany, 2011. 63: p.25-31.

5. Wolf, S., and S., Greiner, Growth control by cell wall pectins. Protoplasma, 2012. 249: p.169-175.

6. Tardieu, F., et al., Genetic and physiological controls of growth under water deficit. Plant Physiology, 2014. 164: p.1628-1635.

7. Cevher-Keskin, B., Microarray Analysis and Functional Characterization of Drought Stress Genes in Wheat, ICGEB CRP/TUR09-03, Final Project Report, 2015.

8. Ye, Z.H., and Varner, J.E. Tissue-specific expression of cell wall proteins in developing soybean tissues. Plant Cell, 1991. 3: p. 23-37.

9. Cassab, G. Plant cell wall proteins. Annu Rev Plant Physiol Plant Molecular Biology, 1998. 49: p. 281-309. 
10. Dunwell, J., et al., Germin and germin-like proteins: evolution, structure, and function. Crit Review Plant Science, 2008. 27: p. 342-375.

11. Wu Y, et al., Expression and distribution of extensins and AGPs in susceptible and resistant banana cultivars in response to wounding and Fusarium oxysporum. Scientific Reports, 2017. 7: p. 42400.

12. Cevher-Keskin, B.C, et al., Quantitative expression analysis of TaMPK4 and TaTIPl genes in drought tolerant and non-tolerant wheat (Triticum aestivum L.) cultivars. Plant Omics Journal, 2015. 8(3): p. 270-277.

13. Keskin B.C, et. al., Expression characteristics of ARF1 and SAR1 during development and the deetiolation process. Plant Biology, 2012. 14: p. 24- 32.

14. Ahn, J.H., A novel extensin gene encoding a hydroxyproline-rich glycoprotein requires sucrose for its wound-inducible expression in transgenic plants. Plant Cell, 1996. 8: p. 1477-1490.

15. Tire, C., et al., Extensin gene expression is induced by mechanical stimuli leading to local cell wall strengthening in Nicotiana plumbaginifolia. Planta, 1994. 195: p. 175-181.

16. Hirsinger, C., et al., Characterization of a tobacco extensin gene and regulation of its gene family in healthy plants and under various stress conditions. Plant Molecular Biology, 1997. 33: p. 279289.

17. Hirsinger, C., et al., The tobacco extensin gene Ext 1.4 is expressed in cells submitted to mechanical constraints and in cells proliferating under hormone control. Journal Experimental Botany, 1999. 50: p. 343-355.

18. Merkouropoulos, G., D.C. Barnett, and A.H. Shirsat, The Arabidopsis extensin gene is developmentally regulated, is induced by wounding, methyl jasmonate, abscisic and salicylic acid, and codes for a protein with unusual motifs. Planta, 1999. 208: p. 212-219.

19. Banerjee, J., M.K. Maiti, Functional role of rice germin-like protein1 in regulation of plant height and disease resistance. Biochem Biophys Res Communication, 2010. 394(1): p. 178-183.

20. Zhang, X., Y. Ren, J. Zhao, Roles of extensins in cotyledon primordium formation and shoot apical meristem activity in Nicotiana tabacum. Journal of Experimental Botany, 2008. 59: p. 4045-4058.

21. Velasquez, S.M., et al., O-glycosylated cell wall proteins are essential in root hair growth. Science, 2011. 332: p.1401-1403.

22. Velasquez, M., et al., Recent advances on the posttranslational modifications of EXTs and their roles in plant cell walls. Frontiers in Plant Science, 2012. 3: p. 93.

23. Pereira, C.S., et al., Extensin network formation in Vitis vinifera callus cells is an essential and causal event in rapid and H2O2-induced reduction in primary cell wall hydration. BMC Plant Biology, 2011.11: p.106.

24. Chormova, D., and S.C. Fry., Boron bridging of rhamnogalacturonan-II is promoted in vitro by cationic chaperones, including polyhistidine and wall glycoproteins. New Phytologist, 2016. 209: p. 241-251.

25. Sujkowska-Rybkowska M, and W. Borucki, Accumulation and localization of extensin protein in apoplast of pea root nodule under aluminum stress. Micron, 2014. 67: p. 10-19.

26. Zhang C., et al., Characterization of NtREL1, a novel root-specific gene from tobacco, and upstream promoter activity analysis in homologous and heterologous hosts. Plant Cell Reports, 2016. 35: p.757-769.

27. Showalter, A.M. Structure and function of plant cell wall proteins. Plant Cell, 1993. 5: p. 9-23.

28. Attard, A., et al., The immediate activation of defense responses in Arabidopsis roots is not sufficient to prevent Phytophthora parasitica infection. New Phytologist, 2010. 187: p. 449-460.

29. Balmer D, et al., Induced resistance in maize is based on organ-specific defense responses. The Plant Journal, 2013. 74: 213-225.

30. Widman, N., et al., Epigenetic differences between shoots and roots in Arabidopsis reveals tissuespecific regulation. Epigenetics, 2014. 9: p. 236-242.

31. Bucher, M., et al., The Expression of an Extensin-Like Protein Correlates with Cellular Tip Growth in Tomato. Plant Physiology, 2002. 128: p. 911-923 
32. Castilleux, R., et al., Cell wall extensins in root-microbe interactions and root secretions Journal of Experimental Botany, 2018. 69(18): p. 4235-4247, https://doi.org/10.1093/jxb/ ery238

33. Zabotin, A.I., et al., Alterations in cell walls of winter wheat roots during low temperature acclimation. J. Plant Physiology, 1998. 152: p.473-479.

34. Imin, N., et al., Effect of early cold stress on the maturation of rice anthers. Proteomics, 2004. 4: p.1873-1882.

35. Seki, M., et al., Monitoring the expression profiles of 7000 Arabidopsis genes under drought, cold and high-salinity stresses using a full-length cDNA microarray. Plant Journal, 2002. 31: p. 279292.

36. Shi, H., AtHAP5A modulates freezing stress resistance in Arabidopsis through binding to CCAAT motif of AtXTH21. New Phytologist, 2014. 203: p. 554-567.

37. Membré, N., et al., Arabidopsis thaliana germin-like proteins: common and specific features point to a variety of functions. Planta, 2000. 211(3): p. 345-354.

38. Federico, M.L., et al., Spatial and temporal divergence of expression in duplicated barley germinlike protein-encoding genes. Genetics, 2006. 174(1): p.179-190.

39. Zimmermann, G., et al., The multigene family encoding germin-like proteins of barley. Regulation and function in basal host resistance. Plant Physiology, 2006, 142(1): p. 181-192

40. Manosalva, P., et al., A germin-like protein gene family functions as a complex qtl conferring broad-spectrum disease resistance in rice. Plant Physiology, 2008. 149(1): p. 286-296

41. Keskin, B.C, et al., Abscisic acid regulated gene expression in bread wheat (Triticum aestivum L.) Australian J Crop Science, 2010. 4: p. 617-625

42. Yi, H., and Richards, E.J., A cluster of disease resistance genes in Arabidopsis is coordinately regulated by transcriptional activation and RNA silencing. Plant Cell, 2007. 19(9): p. 2929-2939 